\title{
Studies on a Novel Safety Catch Linker Cleaved by Pummerer Rearrangement
}

\author{
Chih-Ho Tai, Hsiao-Ching Wu and Wen-Ren $\mathrm{Li}^{*}$ \\ Department of Chemistry, National Central University, Chung-Li, Taiwan, 32054 \\ Fax: $(+886)-3-427-7972$ \\ ch01@ncu.edu.tw
}

\section{Supporting Information}

Experimental Section: General.......................................... 1

Representative experimental procedures......................................... 2

Copies of ${ }^{1} \mathrm{H}$ and ${ }^{13} \mathrm{C}$ NMR spectra of some compounds in Table 1 ....................S4

\section{Experimental Section}

General. All reactions were carried out under argon with dry, freshly distilled solvents and oven- or flame-dried glassware. Moderate-scale reactions (100-500 mg of resin) were carried out using flasks fitted with a glass frit at the bottom and a sidearm connected to a valve. All solid phase reactions were agitated by variable speed orbital mixer. Prior to carrying out reactions, the polymer-bound starting material was allowed to swell in the reaction solvent for 10-20 min under an inert atmosphere. For the library production (<80 mmol/reaction), we utilized an ACT (Advanced ChemTech) LabTech Personal Muttiple Organic Synthesizer, platform III system, equipped with an ARES 48-well Teflon pressure reaction block and cleavage module. Merrifield resin was obtained from SIGMA (200-400 mesh; 1\% cross-linked; loading: $0.79 \mathrm{mmol} / \mathrm{g}$; Lot 23H0597). All resins used were washed and dried by passing nitrogen through them for 20-30 min. Chromatography was carried out on Merck silica gel 60 (particle size 240-400 mesh). ${ }^{1} \mathrm{H}$ and ${ }^{13} \mathrm{C}$ NMR spectra were recorded on a Brucker DRX-200 and AVANCE-500MHz solution (gel-phase) NMR spectrometer (see attached spectra). All reactions were monitored by the above magic angle spinning gel-phase NMR. 


\section{Representative experimental pProcedures (synthesis of compound 11 from Merrifield resin)}

Resin-bound safety-catch linker 3: Merrifield resin (200 $\mathrm{mg}, 0.158 \mathrm{mmol}$ ) was suspended in DMF $(1.5 \mathrm{~mL})$ and was treated with $p$-tritylsulfanyl phenol $(174.5 \mathrm{mg}$, $0.474 \mathrm{mmol})$ and $60 \% \mathrm{NaH}(19.0 \mathrm{mg}, 0.473 \mathrm{mmol})$. The reaction mixture was agitated for $24 \mathrm{hrs}$ at room temperature, flushed and washed with $\mathrm{DMF}(2 \mathrm{~mL} \times 2)$ and $\mathrm{CH}_{2} \mathrm{Cl}_{2}$ (2 $\mathrm{mL} \times 2$ ). The resulting resin was dried in vacuo to provide $p$-tritylsulfanyl protected linker resin $\mathbf{2}$. The resin $\mathbf{2}$ was then treated with a solution of trifluoroacetic acid (TFA) $(0.2 \mathrm{~mL})$ in $\mathrm{CH}_{2} \mathrm{Cl}_{2}(2 \mathrm{~mL})$ for $3 \mathrm{hrs}$ at room temperature. The reaction mixture was then filtered and rinsed with $\mathrm{CH}_{2} \mathrm{Cl}_{2}(3 \mathrm{~mL} \times 3)$ to afford the resin-bound safety-catch linker 3.

Resin-bound compound 9: The obtained resin 3 was swelled with DMF (2 mL) and was treated with bromoethylamine $(97 \mathrm{mg}, 0.474 \mathrm{mmol})$ and sodium acetate $(32.2 \mathrm{mg}, 0.474$ mmol) under an argon atmosphere. The solution was agitated for $12 \mathrm{hrs}$ at room temperature, flushed and washed with $\mathrm{DMF}(2 \mathrm{~mL} \times 2)$ and $\mathrm{CH}_{2} \mathrm{Cl}_{2}(2 \mathrm{~mL} \times 2)$. The resin was dried in vacuo. To the above resin in DMF $(2 \mathrm{~mL})$ was added Boc-L-phenylanaline $\quad(125 \quad \mathrm{mg}, \quad 0.474 \quad \mathrm{mmol}) \quad$ and 2-(1H-benzotriazo-1-yl)-1,1,3,3-tetramethyluronium hexafluorophosphate (HBTU) (179 $\mathrm{mg}, 0.474 \mathrm{mmol}$ ) followed by $N, N$-diisopropylethylamine (DIPEA) $(0.137 \mathrm{~mL}, 0.790$ mmol) at $0{ }^{\circ} \mathrm{C}$. The solution was then shaken for $6 \mathrm{hrs}$ at room temperature, flushed and washed with DMF (2 mL x 3) and $\mathrm{CH}_{2} \mathrm{Cl}_{2}(2 \mathrm{~mL} \times 2)$ to afford the polymer bound compound 9.

Resin-bound compound 10: The resin 9 was first treated with a solution of trifluoroacetic acid (TFA) $(0.2 \mathrm{~mL})$ in $\mathrm{CH}_{2} \mathrm{Cl}_{2}(2 \mathrm{~mL})$ for $1 \mathrm{~h}$ at room temperature. The reaction mixture was filtered and rinsed with $\mathrm{CH}_{2} \mathrm{Cl}_{2}(3 \mathrm{~mL} \times 3)$ to afford the resin-bound free amine. To the resulting resin in $\mathrm{CH}_{2} \mathrm{Cl}_{2}(2 \mathrm{~mL})$ was added trimethylamine (TEA) $(0.11 \mathrm{~mL}, 0.79 \mathrm{mmol})$ followed by benzoyl chloride $(0.055 \mathrm{~mL}$, $0.474 \mathrm{mmol})$. The solution was agitated at room temperature for $3 \mathrm{hrs}$. Then the reaction mixture was flushed and washed with DMF $(2 \mathrm{~mL} \times 3)$ and $\mathrm{CH}_{2} \mathrm{Cl}_{2}(2 \mathrm{~mL} \times 3)$. The resulting resin $\mathbf{1 0}$ was dried in vacuo.

N-[1-(2-Hydroxy-ethylcarbamoyl)-2-phenyl-ethyl]-benzamide 11: The above resin 10 was swelled with $\mathrm{CH}_{2} \mathrm{Cl}_{2}(1.6 \mathrm{~mL})$ and was treated with $t$-BuOOH $(0.252 \mathrm{~mL}, 1.264$ $\mathrm{mmol}$ ) and CSA (36 mg, $0.158 \mathrm{mmol})$. The solution was agitated at room temperature for 
12 hrs. The resin was then flushed and washed with DMF (2 $\mathrm{mL} \times 3)$ and $\mathrm{CH}_{2} \mathrm{Cl}_{2}(2$ $\mathrm{mL} \times 3$ ), and dried by passing nitrogen through it. Then this resin was swelled with THF $(0.6 \mathrm{~mL})$ and was added dropwise $1.5 \mathrm{~mL}$ of a solution containing $0.06 \mathrm{~mL}$ of tricholoroacetic anhydride (TCAA) and $1.44 \mathrm{~mL}$ of THF at ice-bath temperature. The solution was slowly warmed to room temperature and allowed to mix for $45 \mathrm{~min}$. at room temperature. The reaction mixture was then flushed and washed with DMF $(2 \mathrm{~mL} \times 3)$ and $\mathrm{CH}_{2} \mathrm{Cl}_{2}(2 \mathrm{~mL} \times 3)$. The resin was then suspended in THF $(2 \mathrm{~mL})$ and was treated with TEA $(0.022 \mathrm{~mL}, 0.158 \mathrm{mmol})$ and $\mathrm{EtOH}(0.009 \mathrm{~mL}, 0.158 \mathrm{mmol})$. After the solution was agitated for $2 \mathrm{hrs}$ at room temperature, $\mathrm{NaBH}_{4}(11 \mathrm{mg}, 0.316 \mathrm{mmol})$ was added and the suspension was agitated for another $2 \mathrm{hrs}$. After this time, the resin was filtered and the filtrate was concentrated in vacuo. The resulting residue was purified by column chromatography, eluting with EtOAc/hexane (1:9) to afford compound 11 (36.1 $\mathrm{mg}$ ) as a white solid in $73 \%$ yield upon recrystalization from $\mathrm{CH}_{2} \mathrm{Cl}_{2} /$ hexane. 


\section{Copies of ${ }^{1} \mathrm{H}$ and ${ }^{13} \mathrm{C}$ NMR spectra of some compounds in Table 1:}

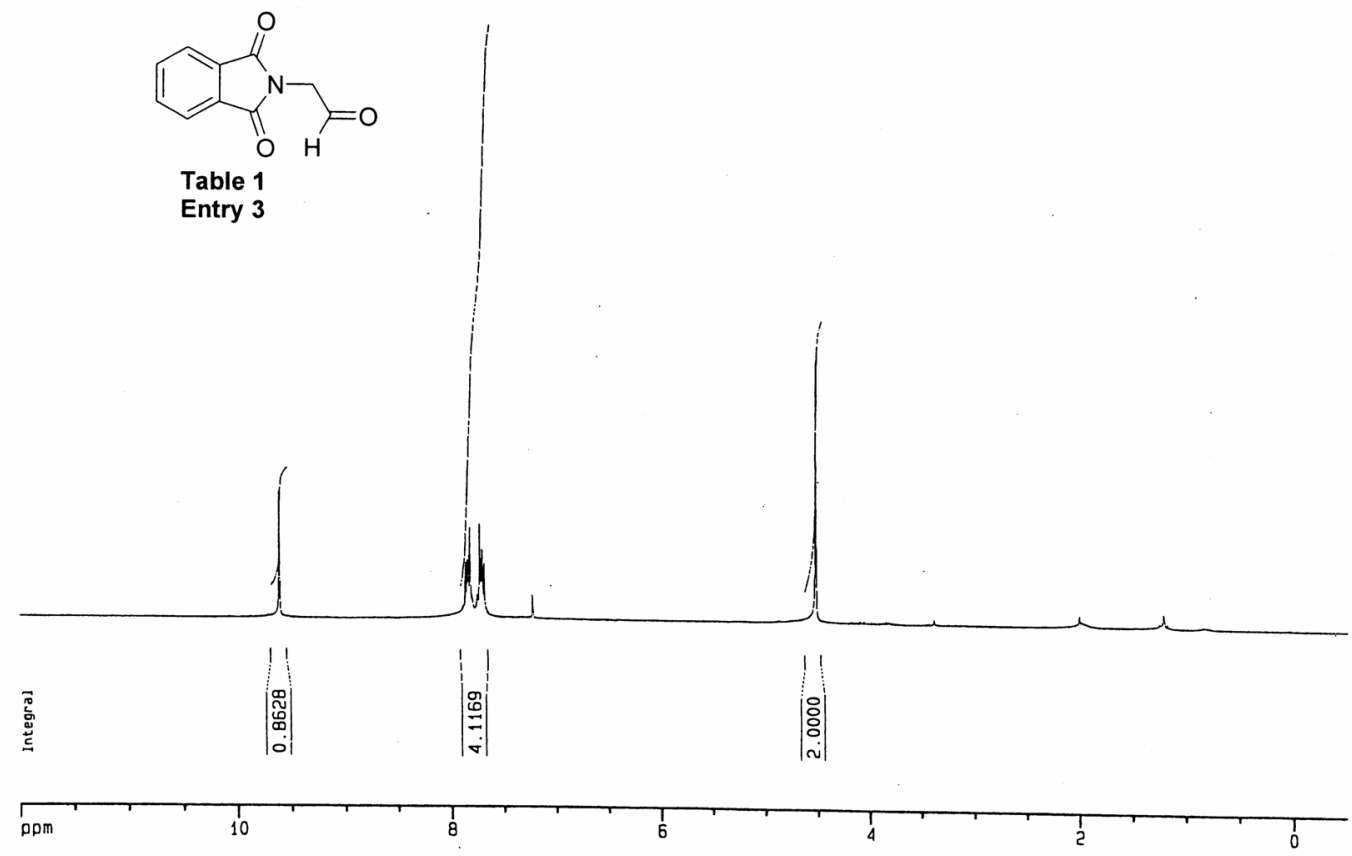

${ }^{\mathrm{l}} \mathrm{H}$ NMR spectrum of N-(2-hydroxy-ethyl)-phthalimide
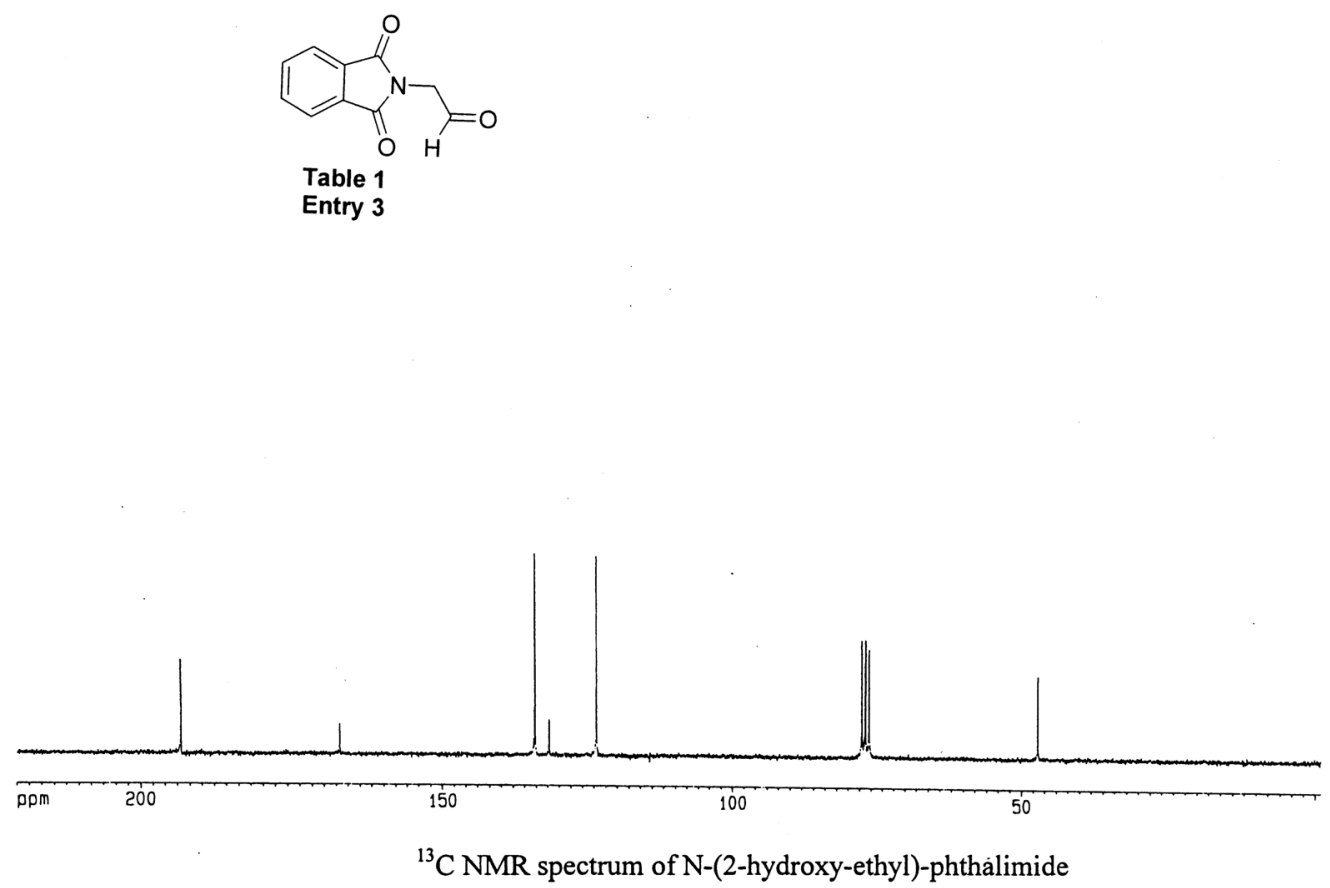

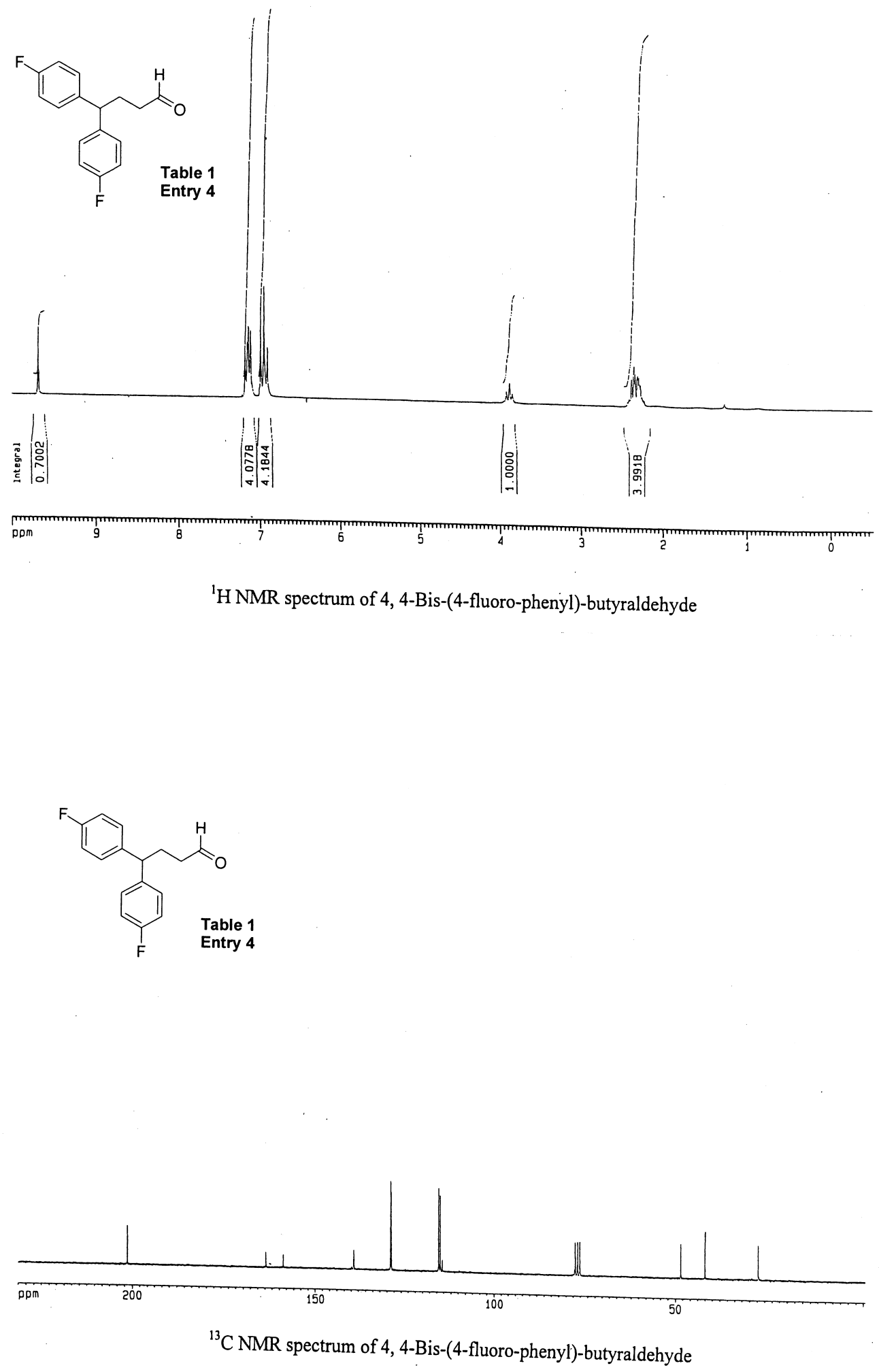


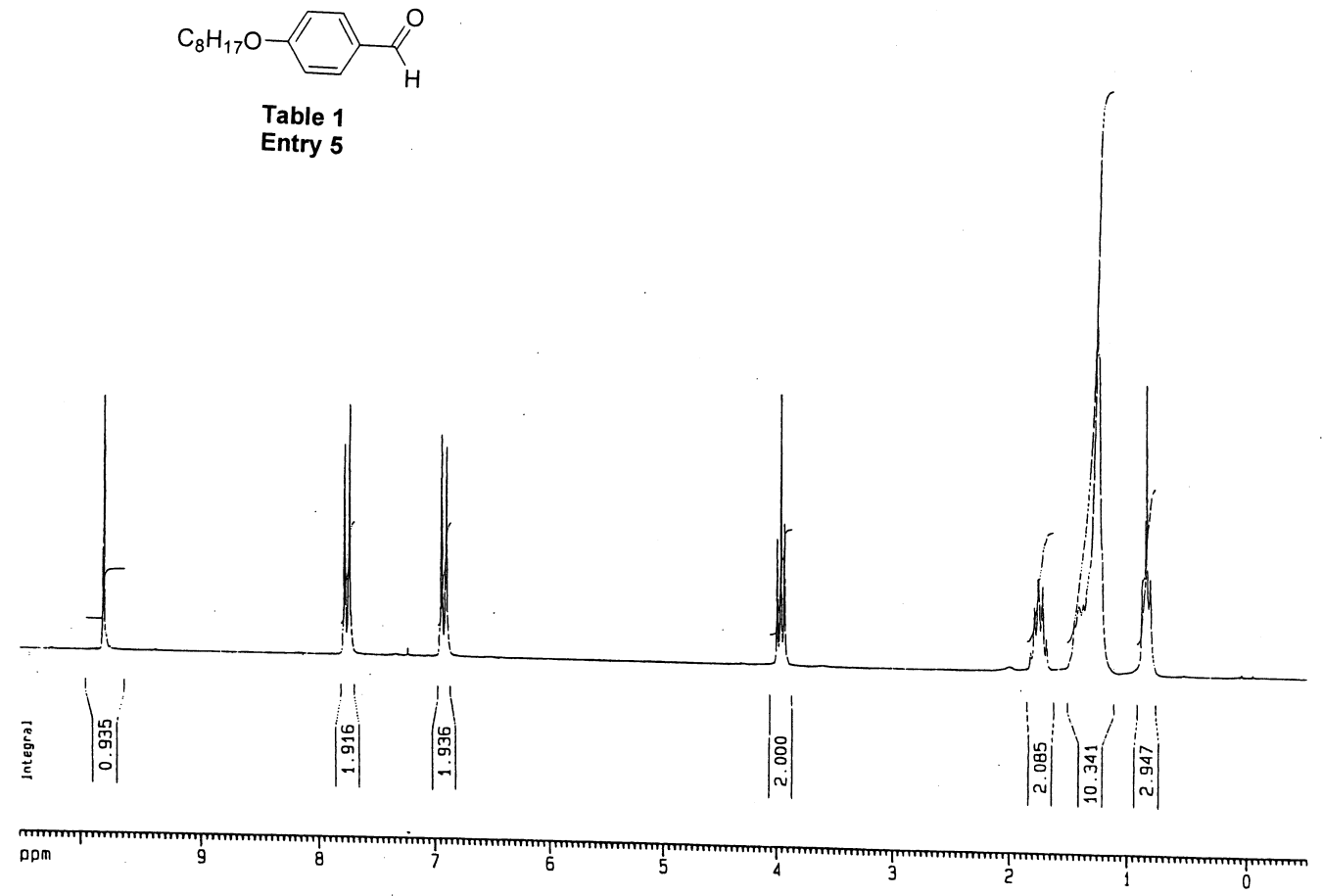

${ }^{1} \mathrm{H}$ NMR spectrum of 4-Octyloxy-benzaldehyde

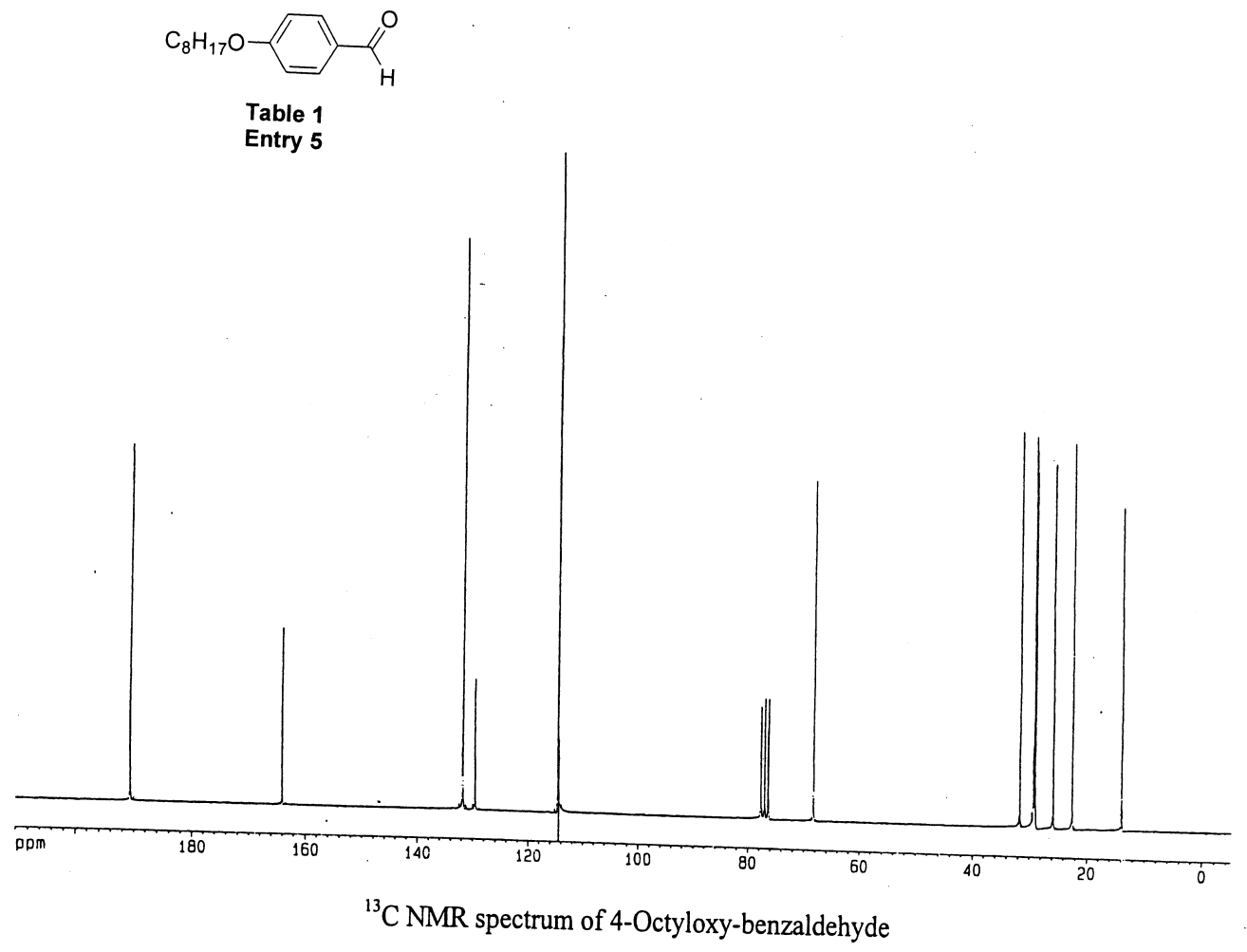



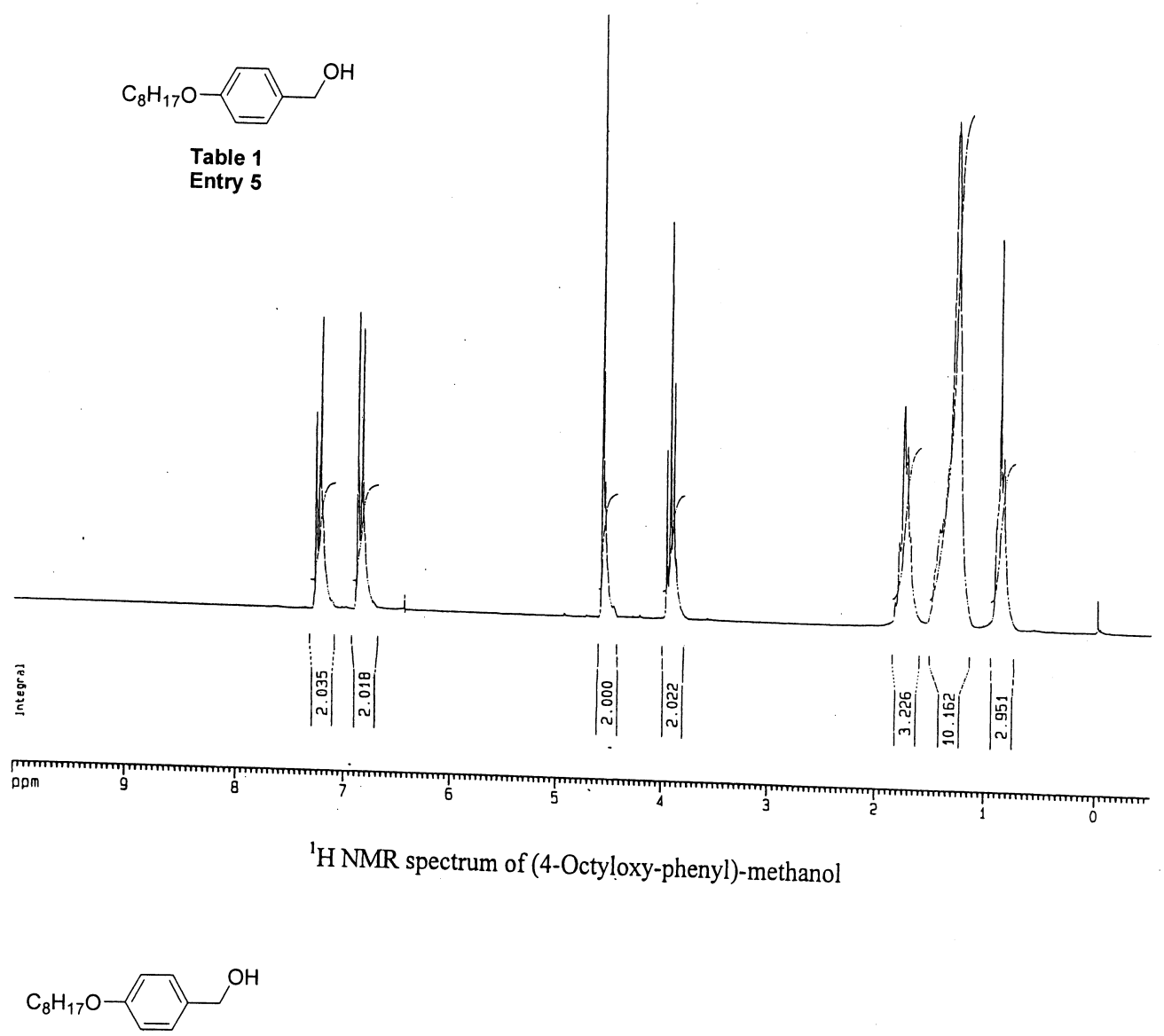

Table 1

Entry 5

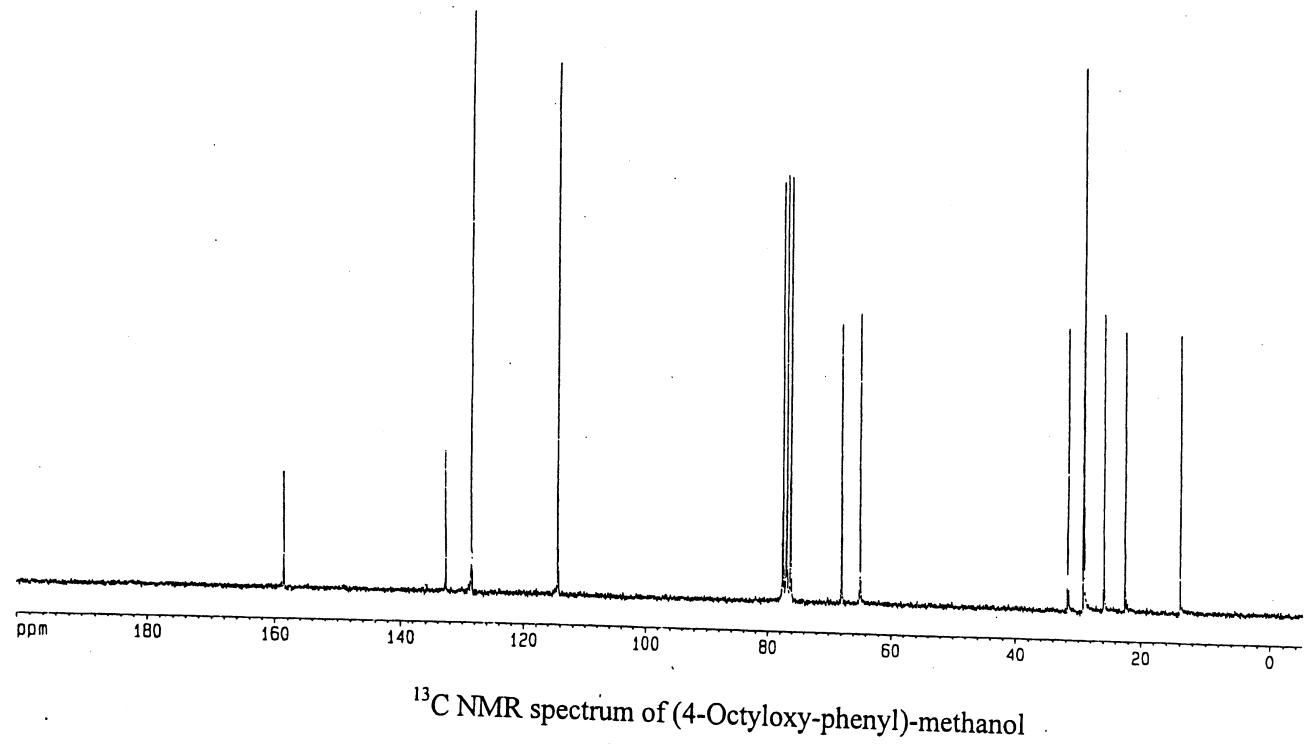



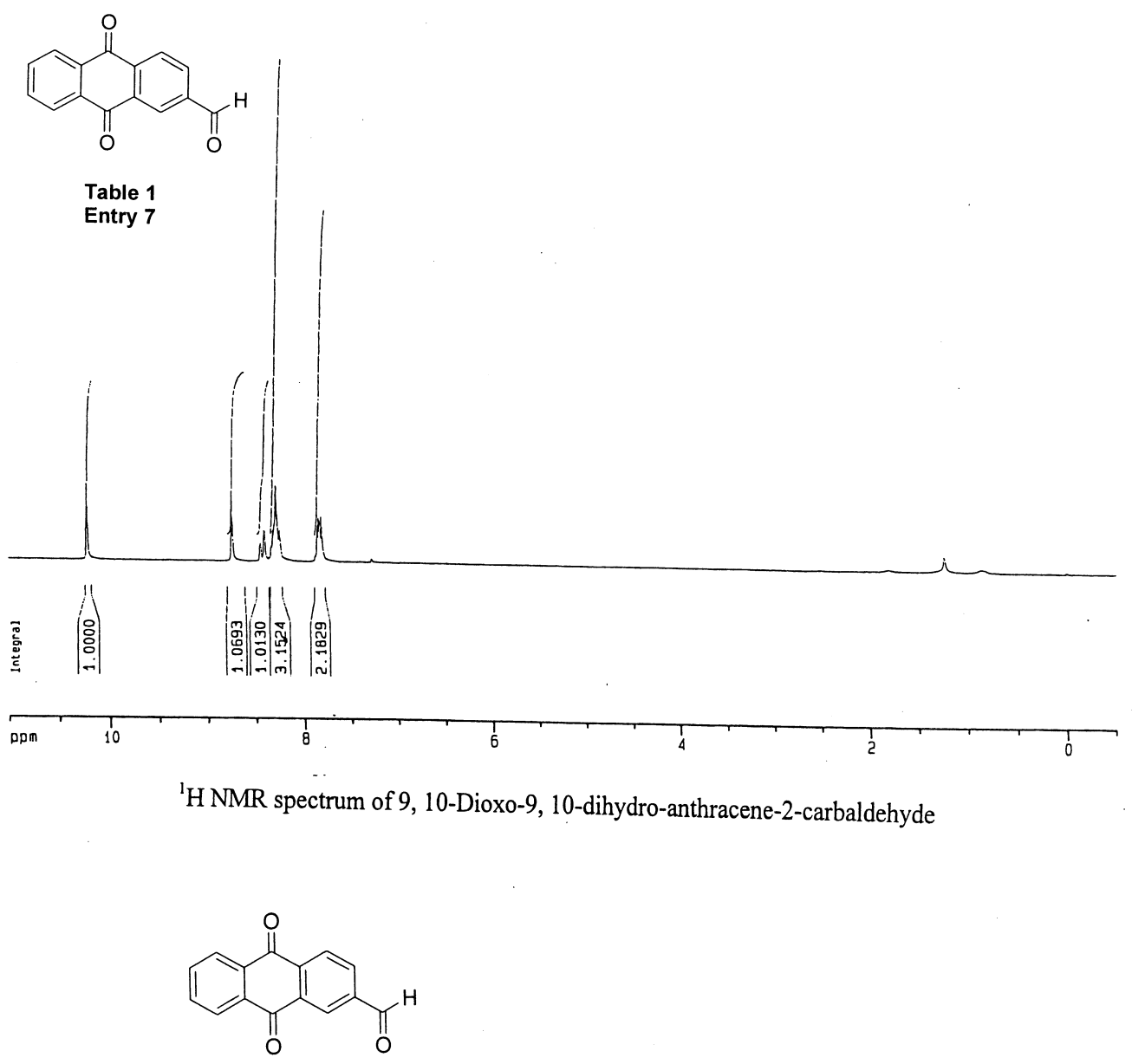

Table 1 Entry 7

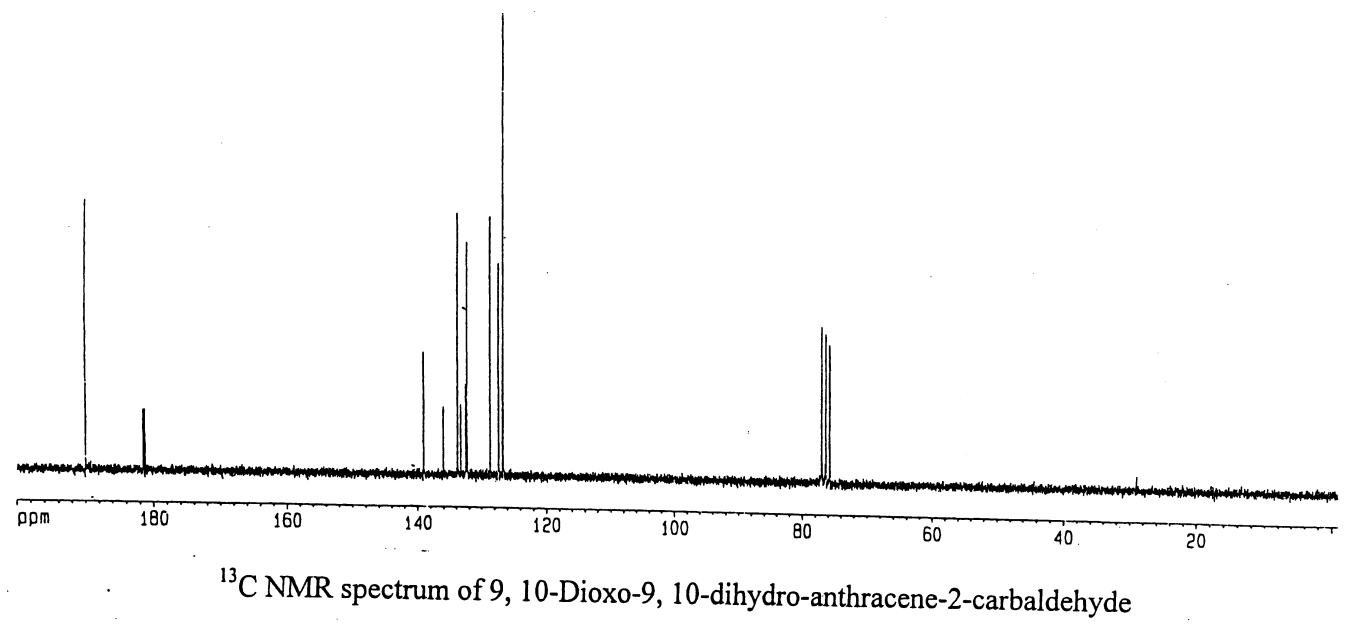



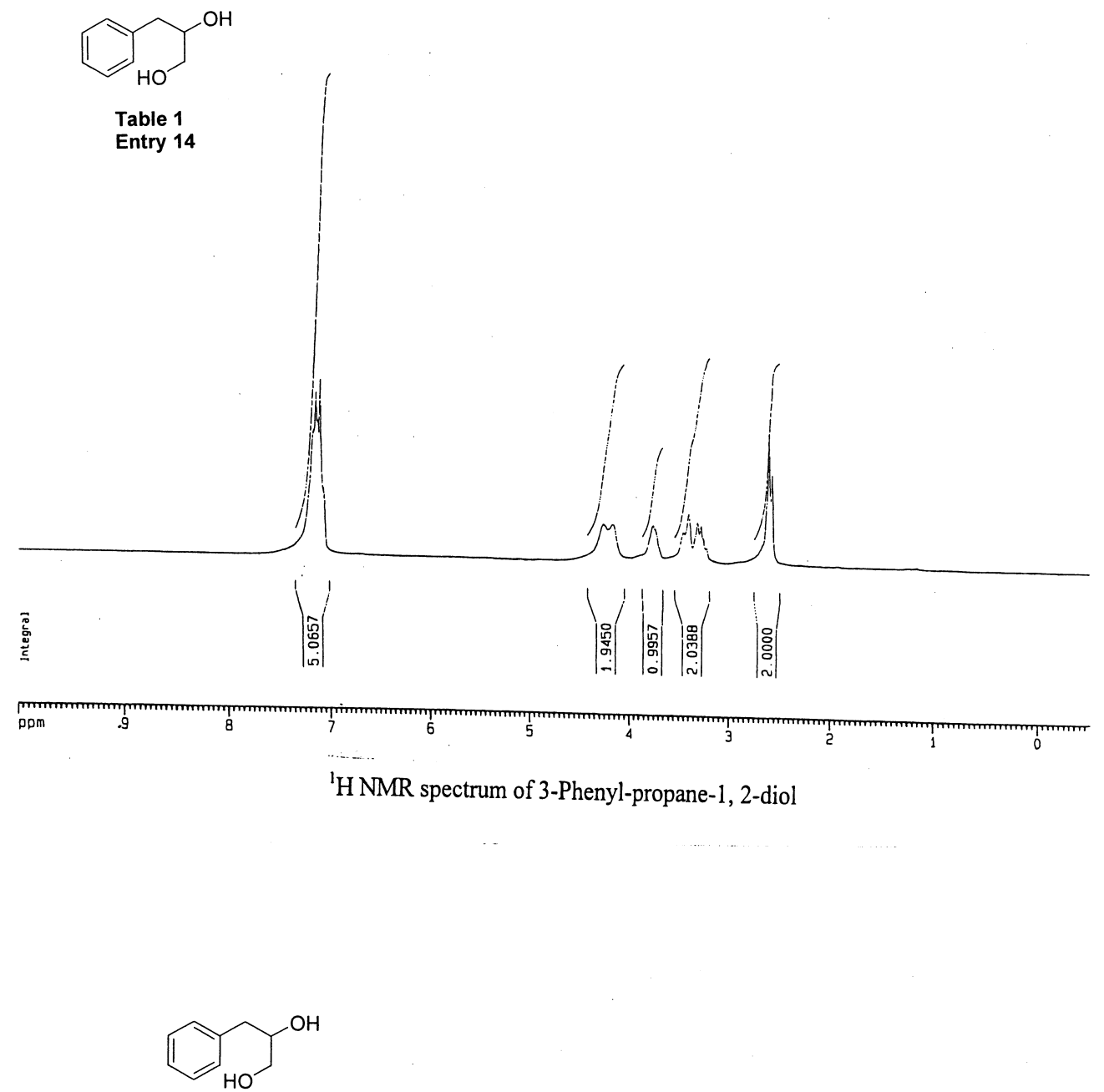

Table 1

Entry 14

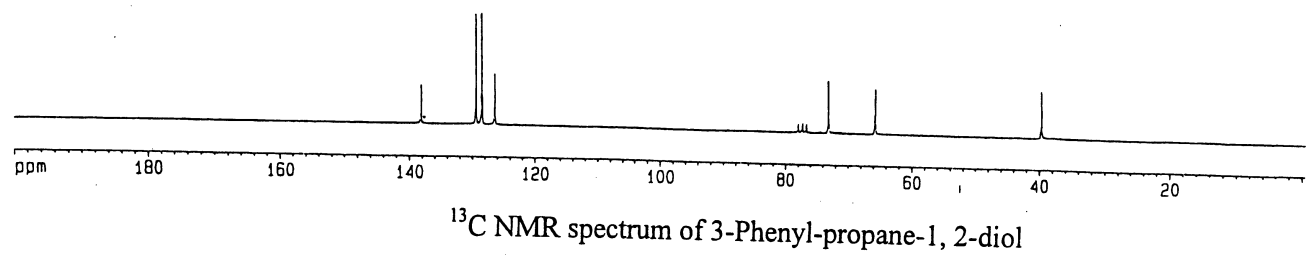




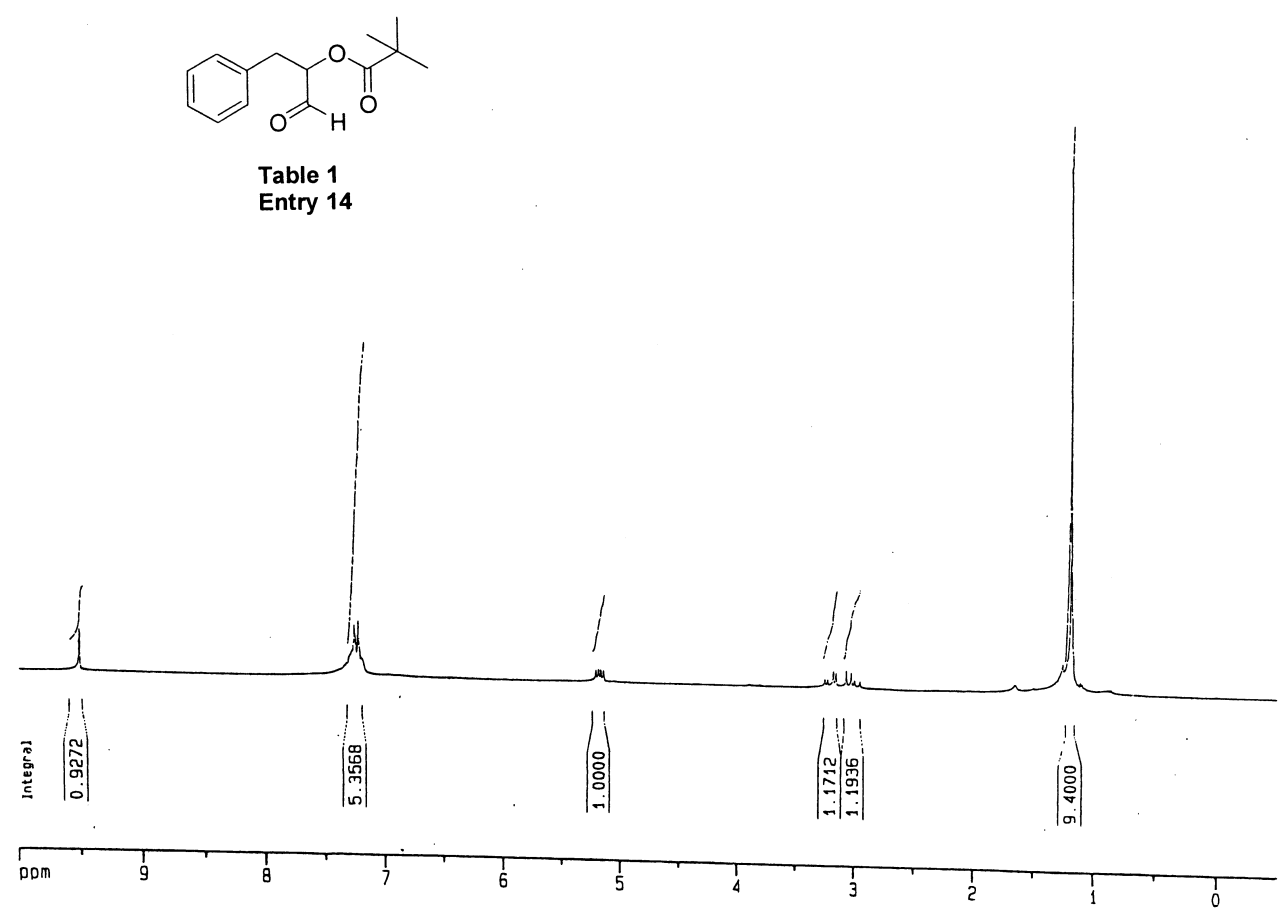

${ }^{1} \mathrm{H}$ NMR spectrum of 2, 2-Dimethyl-propionic acid 1-formyl-2-phenyl-ethyl ester

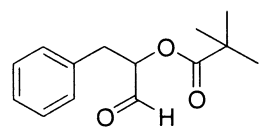

Table 1

Entry 14

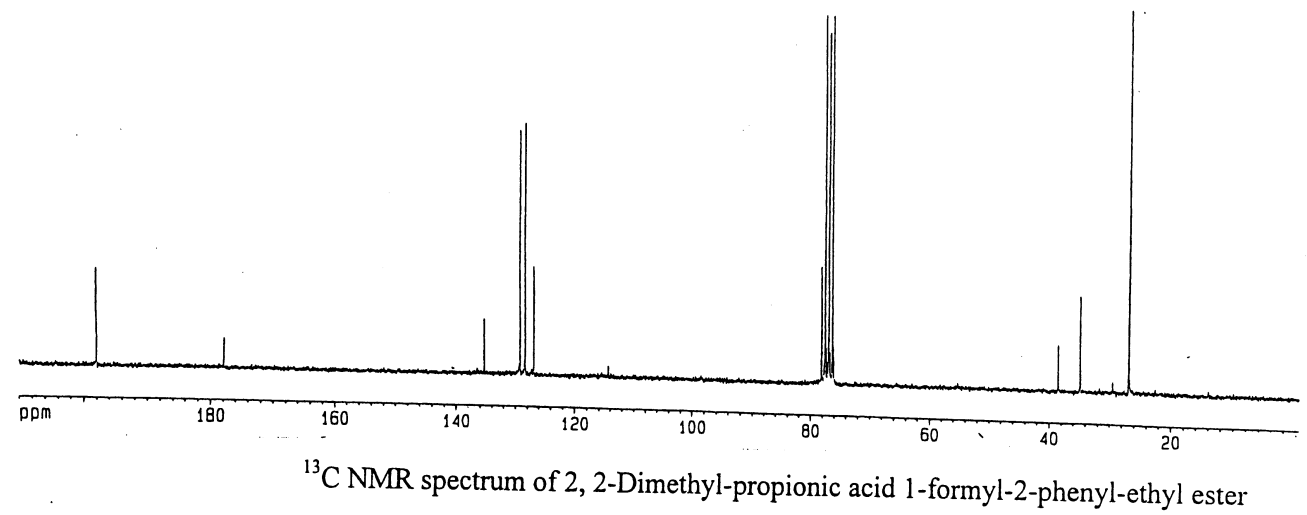




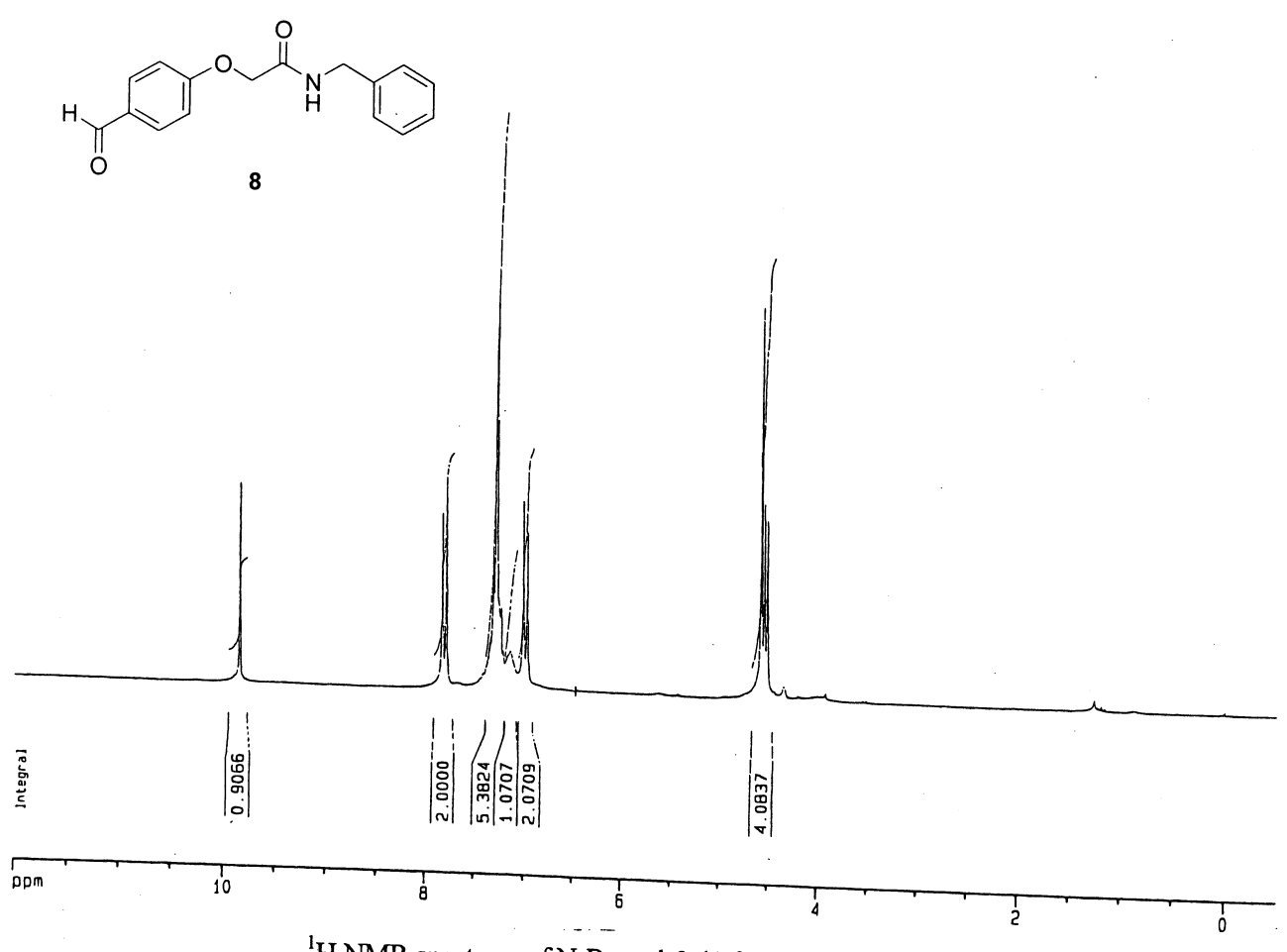

${ }^{1}$ H NMR spectrum of N-Benzyl-2-(4-formyl-phenoxy)-acetamide

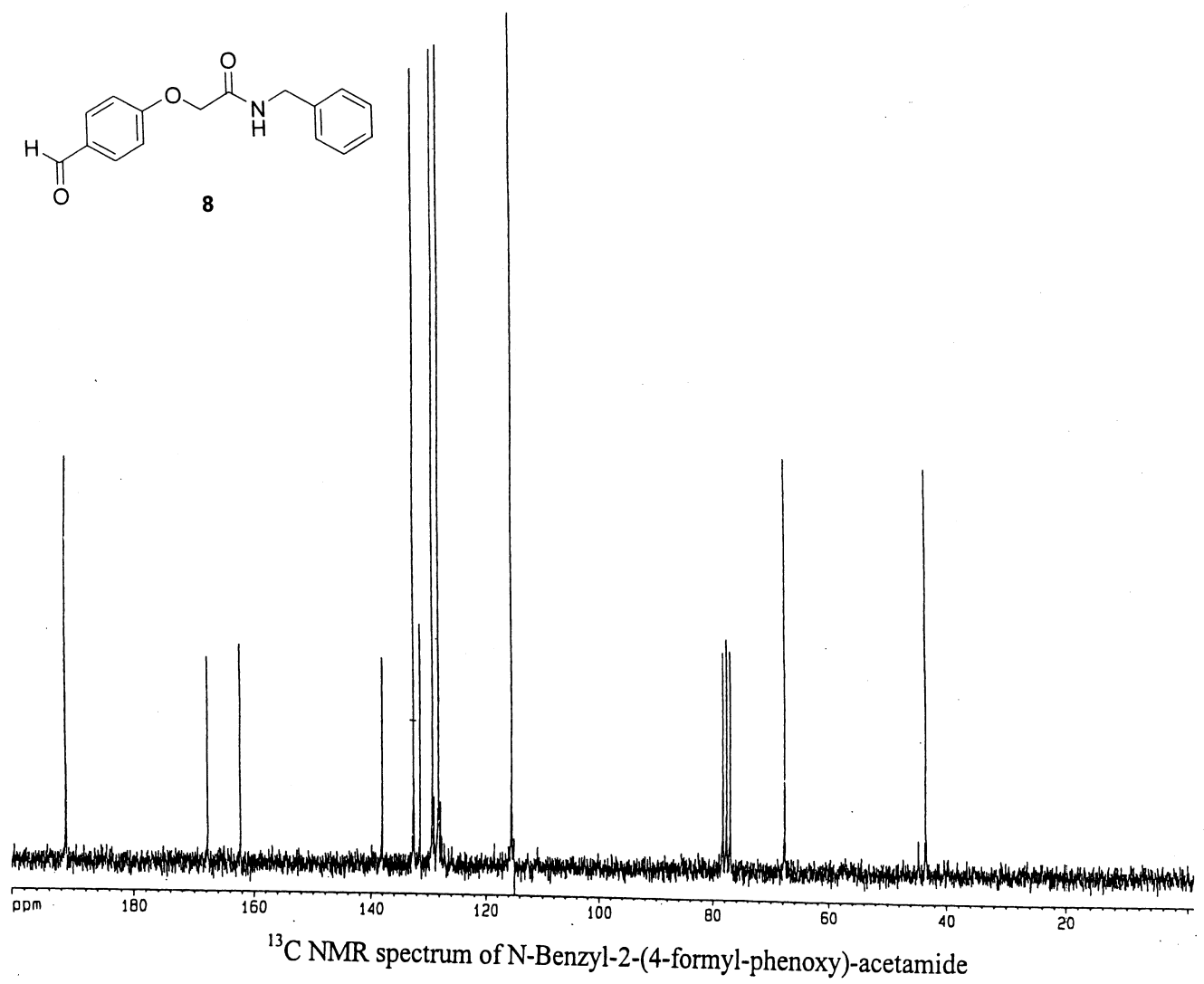



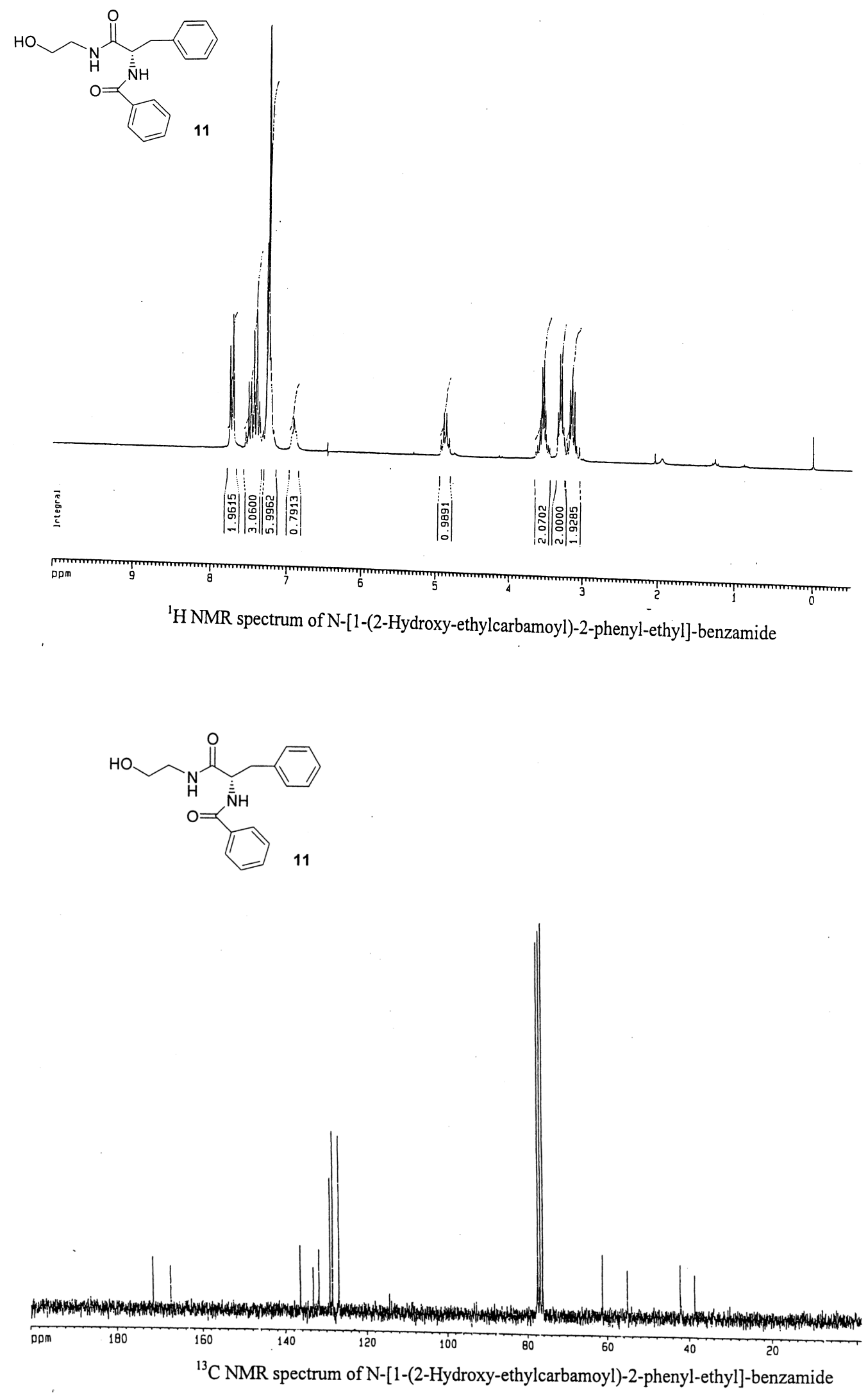